\title{
BIOLOGICAL SECURITY OF THE SARS-COV-2 (COVID-19) INFECTION IN LARGE WORKPLACES OUTSIDE THE HEALTHCARE SECTOR - AN EPIDEMIOLOGIST'S POINT OF VIEW
}

\author{
Wojciech Hanke ${ }^{1}$, Patrycja Pietrzak² \\ ${ }^{1}$ Nofer Institute of Occupational Medicine, Łódź, Poland \\ Department of Environmental Medicine \\ ${ }^{2}$ Medical University of Lodz, Łódź, Poland \\ Department of Orthodontics
}

\begin{abstract}
Populations in large workplaces are particularly susceptible to the risk of severe acute respiratory syndrome coronavirus 2 (SARS$\mathrm{CoV}-2)$ infection. In the following article, an attempt has been made to identify main problems regarding the biological security in large workplaces outside the healthcare sector, while simultaneously pointing out the possible solutions to these problems. In this article, a literature review was performed with regard to publications that have been published within the last 4 months, concerning the issue of risk factors with regard to SARS-CoV-2 infections in large populations. Experts' opinions and statements released by institutions working in this field were also taken into consideration. On the basis of the available publications, key procedures to protect workers in large workplaces against COVID-19 were established. One of these key factors is infection prevention. It is commonly known that, due to limited possibilities of identifying infected people that are asymptomatic, physical distance in the whole employee population should be kept; personal protective equipment (PPE) should be used and tele-work should be implemented. The results of recent research have shown that, apart from airborne ways of transmission, there also exists a possibility of getting infected by coming into contact with contaminated surfaces and objects. Therefore, frequent disinfection of rooms and work tools is essential. In the current situation, due to the lack of a vaccine, only going through the COVID-19 disease, either in a symptomatic or asymptomatic form, significantly increases the chances of developing natural immunity. The means of preventing SARS-CoV-2 infections include quickly identifying the infected people on the basis of the symptoms they report, keeping physical distance, using PPE, disinfecting rooms and applying proper ventilation. Limiting the number of workers by implementing a remote work pattern is also recommended. Med Pr. 2021;72(1):89-97
\end{abstract}

Key words: prevention, workplace, workers, viral infection, COVID-19, biological security

Corresponding author: Patrycja Pietrzak, Medical University of Lodz, Department of Orthodontics,

al. Kościuszki 4, 90-419 Łódź, Poland, e-mail: patrycja.pietrzak@umed.lodz.pl

Received: June 13, 2020, accepted: August 10, 2020

\section{INTRODUCTION}

The ongoing COVID-19 pandemic, caused by the severe acute respiratory syndrome coronavirus 2 (SARSCoV-2), developed in December 2019 in the Chinese Province of Hubei. The pandemic has quickly spread from the Province capital, Wuhan, all over the world, and the factors that contributed to that rapid spread included globalization and easy access to travelling. Generally, SARS-CoV-2 is linked to the SARS virus which appeared in 2002 around the world, also in Asia [1]. Based on a recent Italian report, $73.9 \%$ of all infected individuals aged $<60$ years did not develop symptoms (95\% CI: 71.8-75.9\%) [2]. On average, asymptomatic persons seem to account for approx. $40-45 \%$ of all SARS-CoV-2 cases [3].
On the other hand, more severe symptoms such as high fever $\left(>38^{\circ} \mathrm{C}\right)$, dry cough, tiredness (fatigue) and shallow breathing, as well as diarrhea, pharyngitis, cold or sneezing, are present in approximately $5 \%$ of all cases with viral infections and may lead to pneumonia, acute respiratory distress syndrome, sepsis, septic shock and even death. The most frequent incubation periods range $2-14$ days, the median being 5-6 days. In general, older people (seniors) suffering from chronic diseases with coexistent immunodeficiency have a higher risk of developing COVID-19 than younger and middle-aged people $[1,4]$. It has been observed on several occasions that men are at a higher risk of disease development than women. At present, no explanations of the above phenomenon have been found. It is suggested that women might have a stronger reaction of 
the immune system to the infection with regard to both congenital and acquired immunity. A protective role of estrogens has also been reported [5].

The analysis of mortality due COVID-19 in England and Wales found a higher risk among some ethnic groups comparing with those of white ethnicity. After adjusting for age, black males were 4.2 times more likely to die from COVID-19, and in black females this likelihood was 4.3 times higher than in white males and females. People of Bangladeshi and Pakistani, Indian and mixed ethnicities also had an increased risk of death involving COVID-19 compared with those of white ethnicity, this difference being statistically significant [6].

A systematic review of studies focusing on the association between COVID-19 and smoking found that smokers were 1.4 times more likely to have severe outcomes of COVID-19 than non-smokers. Furthermore, smokers were approximately 2.4 times more likely to be admitted to an intensive care unit, and needed mechanical ventilation or died, compared to non-smokers [7].

\section{The COVID-19 pandemic}

\section{compared to other epidemics and pandemics}

The COVID-19 pandemic is not the first pandemic in the history of mankind. Historically, the biggest epidemics were the black death epidemic (1347-1352) with 25 million deaths, a few episodes of the variola pandemics (since 1520) with 56 million deaths overall, and some local epidemics such as the plague epidemic in London (1665-1666) with 100 thousand deaths.

The recent 100-year period has been especially rich in epidemics, including Spanish flu epidemic (19181919) - 40-50 million deaths, Asian flu (1957-1958) approx. 1-2 million deaths, Hong-Kong flu (1968-1970) with approx. 1-4 million deaths, a few episodes of the cholera pandemics (the last one in 2018) - 1 million deaths, the MERS epidemic (2015) - 858 deaths, the swine flu (2009-2010) - approx. 284.5 thousand deaths, Ebola (2014-2016) - 11.3 thousand deaths, and SARS (2002-2003) - 800 deaths.

The HIV/AIDS epidemic that began in 1981 has resulted in 35 million deaths so far and continues to exist. Bird flu has also caused a lot of emotions; however, to date only 1 case (in 2006) of an animal-human virus transmission has been reported [8].

While COVID-19 is frequently compared to seasonal flu, there are significant differences between these 2 infections. The most important one is the longer incubation period of COVID-19 (2-14 days) when compared to flu (2-4 days), which contributes to a higher level of contagiousness concerning people with COVID-19. As regards flu, statistically 1 infected person infects approximately 1.28 people, compared to $2-3$ people in the case of COVID-19 [9]. To date, no valid estimations of either the case fatality rate or the prevalence rate due to COVID-19 have been reported. The case fatality rate for the whole population is probably about $1 \%$, and the prevalence rate is about $1-4 \%$. Both rates are strongly age-dependent, i.e., they increase with age $[10,11]$.

It is worth noting that, in general, the higher the number of cases found in the country, the lower the case fatality rate, which is measured by taking into account the number of deaths due to COVID-19 per all registered cases, the latter being strongly influenced by the number of swabs performed.

Populations in large workplaces are particularly susceptible to the risk of contracting SARS-CoV-2 infection. The problem concerning biological security, although well known in occupational medicine as being present in particular occupational groups, e.g,. in healthcare workers, has become an ongoing issue in practically every population of workers. In the following article, an attempt has been made to identify main problems regarding the biological security in large institutions outside the healthcare sector, while simultaneously pointing out the possible solutions to these problems in order to avoid massive numbers of infected persons.

The authors are aware that few evidence-based solutions are available, and probably none of these has been tested for efficiency. The selection of proposed actions is based on the available information acquired from research data published since the beginning of February 2020.

\section{METHODS}

In this article, a literature review was done with regard to publications that have been published within the last 4.5 months, concerning the issue of risk factors with regard to SARS-CoV-2 infections in large populations.

In the period of February 2, 2020-June 10, 2020, using the following keywords: "COVID-19," "SARSCoV-2," "symptoms" and "asymptomatic," the authors periodically searched the published medical literature using the PubMed service maintained by the U.S. National Library of Medicine of the National Institutes of Health. In addition, they searched for news reports using Google.

The majority of these articles reflected experts' opinions or statements of institutions working in this field. 
Although many scientific reports were published in highly reputable medical journals, not all of them had gone through the full assessment process and, for this reason, they were presented as the so-called preprints. The authors did not intend to provide a bibliographic revision of the evidence and guidelines for preventing COVID-19 at workplaces. They merely expressed their opinion based on a limited number of best-quality evidence available at the time of publication.

\section{Basic issues regarding}

\section{SARS-CoV-2 infection prevention}

The appearance of COVID-19 cases in the world has created new challenges for the functional organization of large workplaces. It is common knowledge that SARS$\mathrm{CoV}-2$ is mainly transmitted through airborne droplets, and that keeping the proper physical distance is vital for COVID-19 prevention. According to a recent literature search done by Chu et al. [12], the transmission of viruses is lower with physical distancing of $\geq 1 \mathrm{~m}$, compared with a distance of $<1 \mathrm{~m}$. The use of face masks could result in a large reduction of the infection risk. In addition, N95 or similar respirators may offer stronger protection when compared with disposable surgical masks or similar personal protective equipment (PPE) [12].

Most scientists agree that physical distance should be at least $1.5 \mathrm{~m}$, and if possible $2 \mathrm{~m}$. A proper room ventilation process may also significantly contribute to purifying the air from pathogens, among others, also from SARS-CoV-2 [13]. Recent reviews have indicated that asymptomatic persons seem to account for approx. $40-45 \%$ of SARS-CoV-2 infections. Importantly, they can transmit the virus to others for an extended period, perhaps for $>14$ days [3]. It means that such persons are not aware of being a potential source of infection (a vector). The number of people that are asymptomatic decreases with age. Therefore, young and middle-aged employees have the highest chance of becoming a vector [14]. In order to decrease the risk of infection, wearing a mask that covers one's mouth and nose appears advisable. The mask does not protect the person wearing it, but it offers a high degree of protection for people with whom the vector comes in contact. While material masks are usually sufficient, FFP1 masks, or even FFP2 masks, appear to be the best choice [14].

While sick people can be identified by diagnosing the present symptoms, the most frequent of which are fever $>38^{\circ} \mathrm{C}$, dry cough, shortness of breath (dyspnea), but also smell and taste disorders, dizziness (vertigo), headaches, changes in the skin (rash), the possibilities of diagnosing vectors, i.e., people who were infected with COVID-19 but are asymptomatic, are limited [1521]. As a result, using PPE, including at least face masks, is a general obligation $[14,22,23]$.

Another potential route of infection is coming in contact with contaminated surfaces and objects. The generally applied strategy is the hand hygiene system that consists of frequent hand-washing and disinfection of potentially contagious sources. The use of disposable gloves for hand protection is recommended in order to prevent the transmission of the virus on one's face, especially on the eyes, nose and mouth, including the surrounding tissue, which are highly susceptible to infections [24].

Using PPE requires some knowledge with regard to the basic rules concerning the application safety. If these rules are not complied with, such equipment gives a false impression of protection and may even increase the risk of infection. All the elements mentioned above are the factors shaping the risk of infection and people's behaviors, and have a significant influence on the epidemiological situation in every workplace. This is especially true of large workplaces where the possibilities of performing remote work as well as keeping proper physical distance are limited. At the same time, large workplaces stand better chances of delegating biological security officers and establishing educational channels. They also provide better conditions for shaping health-related self-awareness among employees, in relation to the need of social distancing, wearing masks and hands washing.

All the above actions which serve as protection against SARS-CoV-2 infections are the only possible measures at that moment. The crucial line of defense is going to be the individual immunity which will develop as result of vaccine application. Unfortunately, it is still a distant perspective.

\section{The prevention of COVID-19 - suggestions regarding preventive actions to be taken in large institutions/workplaces outside the healthcare sector} Preventive actions that have been presented in the previous section concern the following issues:

How to identify sick people coming to work?

How to identify asymptomatic, newly infected people coming to work?

How to react to information that potentially infected persons were identified in the workplace?

How to ensure protection against the infection in cases where keeping physical distance is not possible? 
How to organize the working system in order to protect employees against the infection from people outside the workplace?

How to maximally increase room ventilation?

- How to protect oneself against the infection from contaminated objects and surfaces?

When can the person who underwent the COVID-19 infection return to work?

What is the role of employee education?

- Is the COVID-19 vaccine the only solution that serves as a stable protection of the workplace team?

\section{How to identify sick people coming to work?}

Temperature measurement in employees is a popular method which is already applied at workplaces. Employees are also obliged to inform their supervisors whether they have symptoms characteristic of COVID-19 before entering the workplace premises. Providing a possibility for remote communication in that regard would be extremely beneficial. This would, however, require implementing adequate training programs to promote the proper COVID-19 self-awareness in employees. They have to accept the fact that entering the workplace premises in the case when there is even a suspicion of them having COVID-19 symptoms results in other people being at risk. An employee should inform his/her employer about the decision of staying at home (self-isolation) due to the manifestation of symptoms concerning an upper-airway infection, either by phone or by email, and should also receive feedback regarding the necessity of contacting (by phone) the primary healthcare unit which will establish further proceedings (indications, visits). In case an employee suspects that she/he has been infected with SARS-CoV-2 due to contact with a confirmed case, or due to being present in places with confirmed virus transmission, she/he must be informed about the necessity of reporting such a suspicion to the proper sanitary institution, responsible for the registration of such cases, as well as of adhering to official recommendations.

It is well established that the older the population, the higher the risk of developing a symptomatic COVID-19 [8,9]. An especially high risk concerns people suffering from heart diseases, such as hypertension and diabetes mellitus, as well as people who are overweight.

A large workplace is most certainly equipped with a highly-developed work safety department and human resources unit staff. It enables unified standards to be created and, importantly, helps in their efficient execution.
How to identify asymptomatic, newly infected people coming to work?

There are no established research-based possibilities in that regard, as molecular tests aimed at diagnosing SARS-CoV-2 by swabs from the nasopharynx or pharynx appear, on the one hand, unrealistic to be performed at constant intervals. On the other hand, such tests do not have adequate sensitivity, as they are characterized by a high amount of false negative results, especially in people that are asymptomatic [25].

Currently, research is being conducted in order to establish, and then verify, the validation of immunological tests. These tests enable the identification of people with a high immunoglobulin $\mathrm{M}$ level that indicates an early stage of the infection. Unfortunately, these tests are often false positive [25].

As the identification of infected employees in asymptomatic stages is extremely difficult, the implementation of universal prevention methods becomes necessary, i.e., treating everyone as being potentially infected. Preventive measures include wearing masks and keeping physical distance and, when required, also using protective gloves. A risk assessment with regard to the patient's age is also important. Workplaces having younger age structures may have a bigger risk in that regard than the ones with older populations.

\section{How to react to information that potentially infected} persons were identified in the workplace?

In case there is information from a worker that he/she is infected with SARS-CoV-2, it is advisable, without waiting for official action to be taken by sanitary authorities, to implement individual procedures in order to establish with whom, from among all employees, the sick person has recently come in contact. A significant part of contact tracing can be done by phone interviews with an infected person's recent contacts - people who have been within $2 \mathrm{~m}$ for $\geq 15 \mathrm{~min}$, as suggested by the European Centre for Disease Prevention and Control (ECDC) [26].

Such a tracking action will enable the assessment of the scale of the phenomenon and will also help to prepare a security plan for the posts in which the affected people were working. The lower the mobility rate expressed by the affected person, and the smaller the number of employees, the easier the task. If there are any doubts as to whether a given person might have been infected, then, as a rule, he/she should be assumed to have in fact been infected.

Every person should have his/her medical history taken with regard to the occurrence of disease symptoms, 
even if such a procedure took place before the start of work. Contact with an infected person should be established prior to his/her entrance to the workplace premises. $\mathrm{He} / \mathrm{she}$ should also be informed about the need of self-isolation by phone.

The ultimate decision regarding the qualification of potentially infected people rests with the institution that is responsible for the supervision of sanitary conditions.

Recently, several countries have started to test the smartphone apps for digital contact tracing in order to identify people potentially exposed to SARS-CoV-2 who should undergo a self-isolation process with the expectation that they will voluntarily do so [27]. However, no international advice has been proposed as far as this matter is concerned.

\section{How to ensure protection against the infection}

in cases where keeping physical distance

is not possible?

The COVID-19 pandemic creates a situation where every employee may be a vector of infection. The risk of infection increases when physical distance between employees decreases [28]. Such a situation takes place when many people use small rooms, enter elevators, use intra-workplace means of transport, or when they are in social rooms, or in any other situation where the number of people within a given surface is significant. It is difficult to set specific limits in this regard. However, some criteria should be established in each workplace separately, taking into consideration its specific nature. A general rule is that during each gathering consisting of a large group of workers, the proper physical distance should be kept in order to decrease the risk of infection. In the case when keeping a 2-m distance cannot be achieved, wearing protective masks becomes a standard. One should remember that the risk of SARS-CoV-2 infection is especially high in ill-ventilated rooms. In open areas, this risk is much lower, especially if physical distance is maintained [28]. In this aspect, proper work organization, taking into account the rules regarding the SARS-CoV-2 infection prevention, is of great importance.

\section{How to organize the working system}

in order to protect employees against the infection from people outside the workplace?

Two solutions are commonly used: work under extraordinary circumstances and the sanitary regime. Work under extraordinary circumstances is based on changing the working time schedule for employees with a continuous working schedule. After their shift, they do not go home but stay on the workplace premises. The employer should secure their board and lodging, as well as the organization of free time. During that time, other employees stay home and they are asked to minimize social contacts. After a certain time span, determined by the employer, the exchange of employees should take place. Work under extraordinary circumstances creates a huge psychological pressure which needs dedicated support. Furthermore, it is also recommended that employees working under extraordinary circumstances should be accompanied by representatives of the management team.

In contrast, the sanitary regime requires such organization of work which enables reducing the risk of virus transmission from one person to another, especially in groups of employees with a continuous working schedule. Such organization also requires the limitation of mobility at the workplace. For instance, the shift that leaves should not have contact with the shift that comes in. In addition, external contacts with people coming to the workplace from outside should be reduced to the minimum. The formation of a crisis team is recommended, which will be equipped with emergency units. These emergency units would take action in extraordinary or emergency situations, or in respect of such matters that would pose threat to the continuity of a given unit/department. If the character of work so permits, such employees should be put on a remote working schedule. This way, without harm to the most significant processes, the number of people being present on the workplace premises would decrease, which would in turn reduce the probability of new infections.

\section{How to maximally increase room ventilation?}

Due to the fact that SARS-CoV-2 transmission is airborne, it appears necessary to adjust ventilation and air-conditioning systems in buildings, in terms of their efficacy, in order to secure the increase in air exchange. Recommendations concerning this matter have been established by several international groups of experts, for example, the Federation of European Heating, Ventilation and Air Conditioning Associations [29] and the American Society of Heating, Refrigerating and Air-Conditioning Engineers [30]. Technical decisions should be taken by each workplace individually.

How to protect workers against the infection from contaminated objects and surfaces?

As a general rule, the smoother the object, the longer the virus survives on it [31]. Therefore, smooth surfaces 
made of plastic or steel are the most dangerous. If they are being touched during work, for instance, when using handles, tie rods or levers, these tools should be systematically disinfected.

This matter also concerns desktops, tables in social rooms, door-handles and toilet accessories. Main communication areas/pathways and generally accessible places should be disinfected on a regular basis. Adequate instructions regarding proceedings in this matter should be established and distributed. In such situations, gloves that protect employees' hands against an infection should be used. Additionally, such gloves should be disinfected systematically and changed in accordance with the instructions given.

When can the person who underwent the COVID-19 infection return to work?

A person suffering from COVID-19 should undergo self-isolation and, in the case of health complications, should be admitted to a dedicated hospital. After these actions are completed, the person can come back to work on condition that in 2 subsequent tests the presence of SARS-CoV-2 is not confirmed. The above criteria also concern workers in whom the presence of SARS-CoV-2 was diagnosed but no symptoms were present. The ideal situation would be if the employee, having recovered from the disease, acquired immunity against COVID-19. Such a situation probably takes place but it cannot be confirmed in every case. The level of immunity is assessed by conducting immunological tests in order to detect specific immunoglobulins G [32].

In some countries, such possibilities of confirming the state of natural immunity have met with high hopes, being referred to as a specific "immunological passport" [32].

Unfortunately, at the moment, the procedure protocol with regard to immunity presence in a given person cannot be assessed in a reliable manner. Despite the general awareness of the so-called natural immunity, it cannot be easily confirmed. In addition, concerns have been raised that the conduction of research aimed at detecting natural immunity would give rise to employee discrimination. A question should also be addressed whether a person who has been infected with SARS-CoV-2, and especially a person that has already undergone the infection, can be infected again. In a few research papers, it was stated that, in particular, people who underwent COVID-19 tests for the presence of SARS-CoV-2 were positive, but the SARS-CoV-2 concentrations were near the detection limit of the available assays, and they likely did not represent a meaningful clinical or public health risk, especially in the absence of symptoms. However, research makes it clear that any definitive evidence does not exist yet [33].

\section{What is the role of employee education?}

As a society, we were not ready for the arrival of the COVID-19 epidemic. It is necessary to quickly make up for the lost time. Workplaces offer unique opportunities for implementing education programs.

Actions should not only involve education posters, information about hand-washing methods and other sanitary behaviors, or about the necessity to keep a 2-m distance (the best option) between co-workers. First and foremost, they should draw attention to employees' own health.

The employee that has developed self-awareness with regard to the COVID-19 threat will more easily decide on his/her own to stay at home when symptoms suggesting an airway infection, especially cough, shortness of breath (dyspnoea) and fever, are diagnosed.

A good source of information is provided by the guidance prepared by ECDC, by the European Agency for Safety and Health at Workplace, and by the Health and Safety Executive [34,35].

Is the COVID-19 vaccine the only solution

that serves as a stable protection

of the workplace team?

Currently, research is being conducted in order to create a vaccine and perform examinations aimed at assessing its efficacy. Many research units are close to establishing the formula for vaccine synthesis. However, before any such vaccine can be commonly used, it should undergo confirmatory examinations with regard to its safety and effectiveness. The effectiveness is being assessed in clinical-control trials during which randomly selected groups of people who are vaccinated against COVID-19 and groups of people who undergo placebo (neutral substance) vaccination are examined to assess the incidence of the disease. The verification of effectiveness in terms of protection (that means a lower incidence in the group that was vaccinated against COVID-19 than in the control group) with regard to the tested vaccine is essential. In order for such examinations to be reliable, the research should be conducted in different countries and on different populations. It is expected that this process will take approx. 18 months. Taking that into 
consideration, the vaccine will be probably ready in the end of 2021. Most likely, the vaccination will not be obligatory which will give rise to a dilemma of whether to vaccinate or not to vaccinate. This type of a dilemma is already present in the case of common flu vaccinations. Unfortunately, the potential of these vaccinations is not fully used. This situation shows how important the health-related self-awareness among employees is. An investment in this development will increase the coverage of the vaccine.

To sum up, the issues presented above cover several important aspects regarding the COVID-19 prevention in large workplaces. First and foremost, attempts should be made to protect the community of employees against infected persons. However, this is quite a challenge as identiftying such people in the work environment is impossible. The only solution is to keep physical distance and to use PPE.

Infection transmission, apart from airborne droplets, also takes place through coming in contact with contaminated surfaces and objects. Therefore, frequent disinfection of these items is necessary and so is the use of protective gloves. It is expected that the recovery from an asymptomatic SARS-CoV-2 infection, and especially from the fully symptomatic COVID-19 disease, increases the chances of developing natural immunity. As soon as a high percentage $(70-80 \%)$ of employees acquire such immunity, the so-called social immunity can be expected to be gained. This means that immune people will serve as protection for sensitive people. It will prevent the disease from spreading within that community. Until such a status is achieved, it is necessary to wait for the vaccine.

\section{The risk of workplace paralysis,}

when taking into account the employment structure, specificity of mining trade, or power plant trade the aspect of energy security of the country

Every larger group of people, when maintaining close contacts, may be at risk of an uncontrolled development of the COVID-19 epidemic. This applies, in particular, to large workplaces. However, they are not totally defenseless. As long as the rules regarding COVID-19 prevention are implemented with full determination, there is a high chance of avoiding such situations. Being fully aware of the severity of this problem, the authors believe that such actions should be taken as fast as possible, and their implementation should be under a systematic supervision of the management team.

\section{The risk for the future of cities and regions in an industrial monoculture, and a strategic role of the workplace}

The scenario involving an uncontrolled epidemic in a large workplace that serves as a working place for groups of people living in a given region is, by all means, the worst-case scenario. Given the high contagiousness of SARS-CoV-2, it could bring tragic results. Nevertheless, the authors have tried to point out that there are some reasonable grounds to believe that such a turn of events can be avoided.

\section{REFERENCES}

1. Amboss [Internet]. Amboss; 2019 [cited 2020 Jun 11]. COVID-19 coronavirus disease. Available from: https:// www.amboss.com/us/knowledge/COVID-19_\%28corona virus_disease_2019\%29.

2. Poletti P, Tirani M, Cereda D, Trentini F, Guzzetta G, Sabatino G, et al. Probability of symptoms and critical disease after SARSCoV- infection. Quant Biol. In press 2020.

3. Oran DP, Topol EJ. Prevalence of Asymptomatic SARSCoV-2 Infection: A Narrative Review. Ann Intern Med. In press 2020, https://doi.org/10.7326/M20-3012.

4. Beeching NJ, Fletcher TE, Fowler R, editors. Best Practice. Coronavirus disease 2019 (Covid-19) [Internet]. BMJ Publishing Group Ltd; 2020 [cited 2020 Jun 11]. Available from: https://bestpractice.bmj.com/topics/en-gb/3000168/ pdf/3000168/Coronavirus $\% 20$ disease $\% 202019 \% 20$ \%28COVID-19\%29.pdf.

5. Richardson S, Hirsch JS, Narasimhan M, Crawford JM, McGinn T, Davidson KW, et al. Presenting Characteristics, Comorbidities, and Outcomes Among 5700 Patients Hospitalized with COVID-19 in the New York City Area. JAMA. 2020;323(20):2052-9, https://doi.org/10.1001/jama.2020.6775.

6. Office for National Statistics [Internet]. The Office; 2020 [cited 2020 Jun 11]. Coronavirus (COVID-19) related deaths by ethnic group, England and Wales: 2 March 2020 to 10 April 2020. Available from: https://www.ons.gov.uk/peo plepopulationandcommunity/birthsdeathsandmarriages/ deaths/articles/coronavirusrelateddeathsbyethnicgroupenglandandwales/2march2020to10april2020.

7. Vardavas CI, Nikitara K. COVID-19 and smoking: A systematic review of the evidence. Tob Induc Dis. 2020;18(20): 1-4, https://doi.org/10.18332/tid/119324.

8. Medicover [Internet]. Medicover; 2020 [cited 2020 Jun 11]. World pandemics history - SARS-CoV-2 coronavirus compared to other pandemics. Available from: https://www. medicover.pl/en/coronavirus/world-pandemics-historysars-cov-2-coronavirus. 
9. Tang X, Du R-H, Wang R, Cao T-Z, Guan L, Yang C, et al. Comparison of Hospitalized Patients with ARDS Caused by COVID-19 and H1N1. Chest. 2020;26;S0012-3692(20) 30558-64, https://doi.org/10.1016/j.chest.2020.03.032.

10. Oke J, Heneghan C, editors. Global Covid-19 Case Fatality Rates [Internet]. CEBM;2020 [cited 2020 Jun 11]. Available from: https://www.cebm.net/covid-19/global-covid-19case-fatality-rates/.

11. Rajgor DD, Lee MH, Archuleta S, Bagdasarian N, Quek SC. The Many Estimates of the COVID-19 Case Fatality Rate. Lancet Infect Dis. 2020;S1473-3099(20)30244-9, https:// doi.org/10.1016/S1473-3099(20)30244-9.

12. Chu DK, Aki EA, Duda S, Solo K, Yaacoub S, Schünemann HJ. Physical distancing, face masks, and eye protection to prevent person-to-person transmission of SARS-CoV-2 and COVID-19: a systematic review and meta-analysis. Lancet. In press 2020, https://doi.org/10. 1016/S0140-6736(20)31142-9.

13. Lidia Morawska L, Cao J. Airborne Transmission of SARSCoV-2: The World Should Face the Reality. Environ Int. 2020;139:105730, https://doi.org/10.1016/j.envint.2020. 105730.

14. Perencevich EN, Diekema DJ, Edmond MB. Moving Personal Protective Equipment Into the Community Face Shields and Containment of COVID-19. JAMA. In press 2020, https://doi.org/10.1001/jama.2020.7477.

15. Wan S, Xiang Y, Fang W, Zheng Y, Li B, Hu Y, et al. Clinical features and treatment of COVID-19 patients in Northeast Chongqing. J Med Virol. 2020;92(7):797-806, https://doi.org/10.1002/jmv.25783.

16. Guan WJ, Ni ZY, Hu Y, Liang WH, Ou C-Q, He JX, et al. Clinical characteristics of coronavirus disease 2019 in China. N Engl J Med. 2020;382:1708-20, https://doi.org/ 10.1056/NEJMoa2002032.

17. Young BE, Ong SWX, Kalimuddin S, Low JG, Yen Tan S, Loh J, et al. Epidemiologic features and clinical course of patients infected with SARS-CoV-2 in Singapore. JAMA. 2020;323(15):1488-94, https://doi.org/10.1001/jama.2020. 3204.

18. Centers for Disease Control and Prevention [Internet]. The Centers; 2020 [cited 2020 Jun 11]. Symptoms of coronavirus. Available from: https://www.cdc.gov/coronavirus/2019-ncov/symptoms-testing/symptoms.html.

19. Mao L, Jin H, Wang M. Neurologic manifestations of hospitalized patients with coronavirus disease 2019 in Wuhan, China. JAMA Neurol. 2020;77(6):1-9, https:// doi.org/10.1001/jamaneurol. 2020.1127.

20. Recalcati S. Cutaneous manifestations in COVID-19: a first perspective. J Eur Acad Dermatol Venereol. 2020;34(5):e212-3, https//doi.org/10.1111/jdv.16 387.
21. American Academy of Dermatology Association [Internet]. The Academy; 2020 [cited 2020 Jun 11]. COVID-19 dermatology registry. Available from: https://www.aad. org/member/practice/coronavirus/registry.

22. Bourouiba L. Turbulent Gas Clouds and Respiratory Pathogen Emissions: Potential Implications for Reducing Transmission of COVID-19. JAMA. In press 2020, https:// doi.org/10.1001/jama.2020.4756.

23. Javid B, Weekes MP, Matheson NJ. Covid-19: should the public wear face masks? BMJ. 2020;369:m1442, https:// doi.org/10.1136/bmj.m1442.

24. Gupta MK, Lipner SR. Personal Protective Equipment Recommendations Based on COVID-19 Route of Transmission. J M Acad Dermatol. 2020;83(1):e45-6, https://doi.org/10.1016/j.jaad.2020.04.068.

25. Sethurman N, Jeremiah SS, Ryo A. Interpreting Diagnostic Tests for SARS-CoV-2. JAMA. In press 2020, https://doi. org/10.1001/jama.2020.8259.

26. European Centre for Disease Prevention and Control [Internet]. The Centre; 2020 [cited 2020 Jun 11]. Contact tracing for Covid-19: current evidence, options for scaleup and an assessment of resources needed. Available from: https://www.ecdc.europa.eu/sites/default/files/documents/COVID-19-Contract-tracing-scale-up.pdf.

27. Keeling MJ, Hollingsworth TD, Read JM. Efficacy of contact tracing for the containment of the 2019 novel coronavirus (COVID-19). J Epidemiol Community Health. In press 2020, https://doi.org/10.1136/jech-2020-214051.

28. Setti L, Passarini F, De Gennaro D, Barbieri P, Perrone MG, Borelli M, et al. Airborne Transmission Route of COVID-19: Why 2 Meters/6 Feet of Inter-Personal Distance Could Not Be Enough. Int J Environ Res Public Health. 2020;17(8):2932, https://doi.org/10.3390/ijerph 17082932.

29. Nishiura H, Oshitani H, Kobayashi T, Saito T, Sunagawa T, Matsui T, et al. MHLW COVID-19 Response Team, Motoi Suzuki: Closed environments facilitate secondary transmission of coronavirus disease 2019 (COVID-19). MedRxiv. In press 2020, https://doi.org/10.1101/2020.02. 28.20029272.

30. ASHRAE [Internet]. Atlanta: ASHRAE; 2020 [cited 2020 Jun 11]. Position Document on Infectious Aerosols. Available from: https://www.ashrae.org/file\%20library/ about/position\%20documents/pd_infectiousaerosols_ 2020.pdf.

31. Van Doremalen N, Bushmaker T, Dylan H, Morris DH, Holbrook MG, Gamble A, et al. Aerosol and Surface Stability of SARS-CoV-2 as Compared with SARS-CoV-1. N Engl J Med. 2020;382(16):1564-7, https://doi.org/10.11 01/2020.03.09.20033217. 
32. Phelan A. COVID-19 immunity passports and vaccination certificates: scientific, equitable, and legal challenges. Lancet. 2020;395(10237):1595-8, https://doi.org/10.1016/ S0140-6736(20)31034-5.

33. Kirkcaldy RD, King BA, Brooks JT. COVID-19 and postinfection immunity limited evidence, many remaining questions. JAMA. In press 2020, https://doi.org/10.1001/ jama.2020.7869.
34. OSHWiki [Internet]. OSHWiki; 2020 [cited 2020 Jun 11] COVID-19: guidance for the workplace. Available from: https://oshwiki.eu/wiki/COVID-19:_guidance_for_the_ workplace.

35. OSHWiki [Internet]. OSHWiki; 2020 [cited 2020 Jun 11]. COVID-19: Back to the workplace - Adapting workplaces and protecting workers. Available from: https://oshwiki.eu/wiki/COVID-19:_Back_to_the_workplace_-_ Adapting_workplaces_and_protecting_workers.

This work is available in Open Access model and licensed under a Creative Commons Attribution-NonCommercial 3.0 Poland License - http://creativecommons.org/licenses/by-nc/3.0/pl/deed.en. 